\title{
1665/2020: de la peste au corona
}

\section{Werner Bauer}

Dr méd., président de l'Institut suisse pour la formation médicale postgraduée et continue (ISFM)

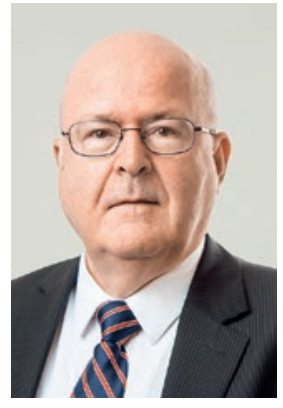

Daniel Defoe (1660-1731) est mondialement connu pour son premier roman Robinson Crusoé. Il a vécu à Londres comme commerçant et journaliste. En 1722, il a publié son Journal de l'Année de la Peste, qui relate, à mi-chemin entre le reportage et le roman, l'épidémie de peste en 1665. Saisissant et évocateur, le récit de Defoe contient des parallèles surprenants avec ce que nous vivons aujourd'hui, notamment en termes de réactions humaines [1]. Je laisse le livre parler de lui-même.

Voici ce que stipulent les ordonnances du lord-maire et des échevins:

Dans toute maison, dès que quelqu'un se plaindra de taches, de rongeurs ou d'enflure en quelque partie $d u$ corps, ou tombera dangereusement malade de toute autre façon sans que les signes indiquent une autre affection, le maître de cette maison en donnera connaissance à l'inspecteur de la santé dans les deux heures qui suivront l'apparition desdits signes.

Aussitôt qu'une personne sera reconnue par cet inspecteur comme atteinte de la peste, elle sera le soir même séquestrée dans la maison. Dans le cas même où le malade ainsi séquestré ne mourrait pas, la maison restera fermée durant un mois [...]

Toute maison contaminée sera marquée d'une croix rouge haute d'un pied au centre de la porte, de façon qu'elle soit bien visible [...]

Les officiers de police veilleront à la fermeture de ces maisons et à leur prise en charge par les gardiens. La fermeture durera quatre semaines après complet rétablissement de la salubrité [...]

Tous spectacles, combats d'ours, jeux, chants de ballades, assauts d'escrime et autres motifs semblables d'attroupements seront formellement interdits. Les contrevenants seront sévèrement punis dans chaque circonscription par l'échevin.

Les descriptions de Daniel Defoe sur les réalités de l'épidémie au quotidien:

Il est vrai que le règlement obligeait les chefs de famille à signaler dans les deux heures à l'inspecteur du quartier où il habitait tout cas de maladie constaté dans sa maison, c'est-à-dire toute personne portant les marques de l'infection; mais ils trouvaient tant d'échappatoires ou tant d'excuses pour leur négligence qu'ils faisaient rare- ment cette notification avant d'avoir pris toutes mesures pour faire esquiver tous ceux qui le voulaient, malades ou non. En cet état des choses, il est aisé de voir qu'il n'y avait pas à se fier à la fermeture des maisons pour arrêter l'épidémie [...]

Ici aussi, je dois faire une remarque au sujet de la façon dont les gens s'infectaient les uns les autres: ce n'était pas seulement des malades que les gens sains prenaient directement le mal, mais aussi des bien-portants [...] Par bien-portants, j'entends ceux qui avaient reçu la contagion, qui l'avaient réellement sur eux et dans leur sang, et dont, cependant, l'aspect extérieur n'en révélait rien; bien mieux, qui ne s'en rendaient pas compte eux-mêmes [...] Ceux-là exhalaient la mort en tous lieux et sur toutes les personnes qui les approchaient [...] Or, il était impossible de reconnaître ces gens, qui, comme je l'ai dit, ignoraient souvent eux-mêmes qu'ils étaient infectés [...]

Je me rappelle que, selon ce que disait toujours mon ami le docteur, il y avait une gamme de drogues et de préparations qui étaient toutes certainement bonnes et utiles en cas d'infection; les médecins pouvaient en faire ou en tirer une variété infinie de médecines, comme les carillonneurs tirent des centaines d'airs différents en changeant ou en intervertissant l'ordre de six cloches seulement [...] D'aucuns pensent que pill. ruft., appelée précisément pilule antipestilentielle, est la meilleure préparation que l'on puisse fabriquer; d'autres estiment que la thériaque de Venise suffit par elle-même à permettre de résister à la contagion [...] Tel est le tempérament irréfléchi de notre peuple [...]: tout comme dans la première terreur de l'infection les gens s'évitaient les uns les autres et s'enfuyaient des maisons et de la cité avec une peur irraisonnée, [...] à présent que l'idée se répandait que la maladie ne s'attrapait plus aussi facilement et que, même si on la contractait, elle n'était plus aussi mortelle, à présent que l'on voyait journellement se rétablir nombre de gens qui avaient été réellement malades, l'on se prit avec empressement d'un tel courage, l'on devint si insoucieux de soi-même et de l'infection que l'on ne fit pas plus de cas de la peste que de quelque fièvre ordinaire, sinon même moins.

\section{Référence}

1 Daniel Defoe. Journal de l'Année de la Peste. Paris: Gallimard; 1982(1722). 